\title{
Sexual Dysfunction and Infertility Amongst Spouses in Adamawa State, Nigeria
}

\author{
Mohammed Aliyu" , Kubkomawa Hayatu Ibrahim², *, Modibbo Abdullahi Abubakar ${ }^{3}$ \\ ${ }^{1}$ Department of Biomedical and Pharmaceutical Technology, School of Science Technology, the Federal Polytechnic, Mubi, Nigeria \\ ${ }^{2}$ Department of Fisheries Technology, School of Agricultural Technology, the Federal Polytechnic, Mubi, Nigeria \\ ${ }^{3}$ Department of Chemical Sciences, School of Science Technology, the Federal Polytechnic, Mubi, Nigeria
}

Email address:

kubkomawa@yahoo.com (K. H. Ibrahim)

${ }^{*}$ Corresponding author

\section{To cite this article:}

Mohammed Aliyu, Kubkomawa Hayatu Ibrahim, Modibbo Abdullahi Abubakar. Sexual Dysfunction and Infertility Amongst Spouses in Adamawa State, Nigeria. American Journal of Health Research. Vol. 9, No. 1, 2021, pp. 1-8. doi: 10.11648/j.ajhr.20210901.11

Received: December 24, 2020; Accepted: January 18, 2021; Published: January 28, 2021

\begin{abstract}
Deterioration in reproductive health and family food sufficiency leading to increase in marital crisis or divorce, arising from sexual dysfunction and infertility amongst spouses in Nigeria is alarming. An investigation was carried out to find the causes, signs and symptoms of sexual dysfunction and infertility amongst spouses in Adamawa State, Nigeria. Respondents were purposively selected with the use of questionnaires for oral interviews, observations and discussions. One hundred volunteer spouses were screened and sent to hospitals for diagnosis of reproductive diseases through culture of their urine, stool, vaginal swabs, semen and prostate content. These specimens were also examined under the electric microscope. Ultrasounds scanning of prostate glands, bladders, kidneys and ovaries or fallopian tubes of the spouses were also carried out to check for abnormalities. The results showed that, $88 \%$ of the spouses suffering from these conditions are youths (the active work force of the nation) between the ages of 20 to 40 years while $12 \%$ are in the age bracket of 50 to 70 years old. The findings indicated that, $90 \%$ of them are married while $10 \%$ are still single. The results showed that, $78 \%$ of the spouses had infection for 1 to 10 years while $22 \%$ had it for more than 11years. The results showed that, $80 \%$ of them contracted the infection through sexual intercourse while $20 \%$ don't know how and where they got infected. The hospital culture of urine, vaginal swabs, semen and prostate content of all the spouses showed negative results. The microscopic examinations of these specimens yielded positive to abdominal Schistosomiasis (bilharziasis). The ultrasound scanning of the prostate glands, kidneys and ovaries/ fallopian tubes revealed abnormalities of various degrees. Spouses with early or mild infections (for 1 to 10years) manifested the first 15 symptoms while those with severe and critical infections (for more than 11years) manifested all the 30 symptoms. Therefore, infections of the urinary bladders, genital organs, prostate glands and kidneys by Schistosome species contracted through sexual intercourse may be responsible for sexual dysfunction and infertility amongst spouses in the study area. There should be proper sensitivity for the diagnosis of mild infections caused by this parasite. Immediate authorities should, as a matter of urgency, initiate and support the development of a drug in commercial quantity that could be used to serve as an intervention programme in Nigeria and the world at large.
\end{abstract}

Keywords: Sexual Dysfunction, Infertility, Spouses, Adamawa State, Nigeria

\section{Introduction ${ }^{1}$}

The role of sexual satisfaction in any healthy romantic relationship is clear and can never be overemphasized. This

\footnotetext{
${ }^{1}$ We, sincerely, wish to express our profound gratitude and unreserved appreciation to tertiary education trust fund (TETFUND) Nigeria for sponsoring this research work.
}

is always associated with high sense of love, sacrifice, commitment, stability in the relationship and reduced rate of divorce in the society. Lack of sexual satisfaction is usually the cause of relationship breakdown, infidelity, infertility and social stigma around the world [6].

Sexual dysfunction is a problem which prevents couples from experiencing satisfaction from sexual response cycle which includes excitement, plateau, orgasm and resolution 
$[24,30]$. Research has also shown that sexual dysfunction may be associated with lack of desire, arousal and orgasm [29]. Sexual dysfunction can also be as a result of a physical or psychological problem. Physical and medical conditions that cause problems with sexual function include sexually transmitted diseases (STD), kidney related infections, liver failure, diabetes, heart diseases, neurological diseases, hormonal imbalances, menopause and alcoholism or drug abuse [8, 3, 31]. In addition, the side effects of certain medications, including some antidepressant drugs, can affect sexual desire and function. While the psychological causes include work-related stress and anxiety, other causes could include concern about sexual performance, marital or relationship problems, depression, feelings of guilt, or the effects of a past sexual trauma [8,3]. These also affect the family food production and economic growth through the health impact measured by disabilities, deformities, loss of productivity, care and treatment caused by these conditions. The conditions are, however, more devastating since they affect all components of human development, including food security, income, health and education [35].

Both men and women of all ages are affected by sexual dysfunction [8, 3]. Sexual dysfunction threatens the wellbeing and future of families in the entire world today [27, 15]. It has social and psychological implications in both male and female spouses [27]. There about 31\% men and $43 \%$ women who experience sexual dysfunction and infertility globally, but find it very difficult to discuss them $[1,33]$. In the United States for instance, about 10\%-50\% men and $25 \%-60 \%$ women suffer from sexual dysfunction [22]. In the African perspective and Nigeria in particular, conjugal unions are sacred and expected to yield sexual excitements and childbearing or procreation. Therefore, intervention programmes to sustain such conjugal unions are necessary and vital [7].

Infertility is a disease of the reproductive system defined by the failure to achieve a clinical pregnancy after 12 months of regular unprotected sexual intercourse [34]. Infertility has always been a paramount issue of concern in human population in the world $[21,5]$. Sexual dysfunctions can also be the cause of infertility or the result of it [32]. In addition, the response to inability to conceive always leads to emotional stress such as anger, anxiety, hopelessness and sadness, which may as well disturb sexual activities and economic productivity in most of the people [12].

The rate of family crisis, broken homes because of sexual dysfunction and infertility, in recent times is on the increase in Nigeria. A lot of men with sexual dysfunction and infertility problems are not able to satisfy their spouses on bed while women with similar cases don't have feelings and hate sex. This affects the physical wellbeing and economic status of the spouses leading to social and psychological problems. The objective of this study is to investigate the causes, signs and symptoms of sexual dysfunction and infertility amongst spouses in Adamawa State, Nigeria. This is to recommend intervention programmes to improve the healthy sexual performance, fertility rate, food sufficiency and economic status of the people.

\section{Materials and Methods}

\subsection{The Study Area}

Adamawa State is located at the area where the River Benue enters Nigeria from Cameroon Republic and is one of the six states in the North-East geopolitical zone of Nigeria. It lies between latitudes $7^{\circ}$ and $11^{\circ}$ North of the Equator and between longitudes $11^{\circ}$ and $14^{\circ}$ East of the Greenwich Meridian [25]. It shares an international boundary with the Republic of Cameroon to the East and inter-state boundaries with Borno to the North, Gombe to the North-West and Taraba to the South-West [3, 9], as shown in Figure 1.

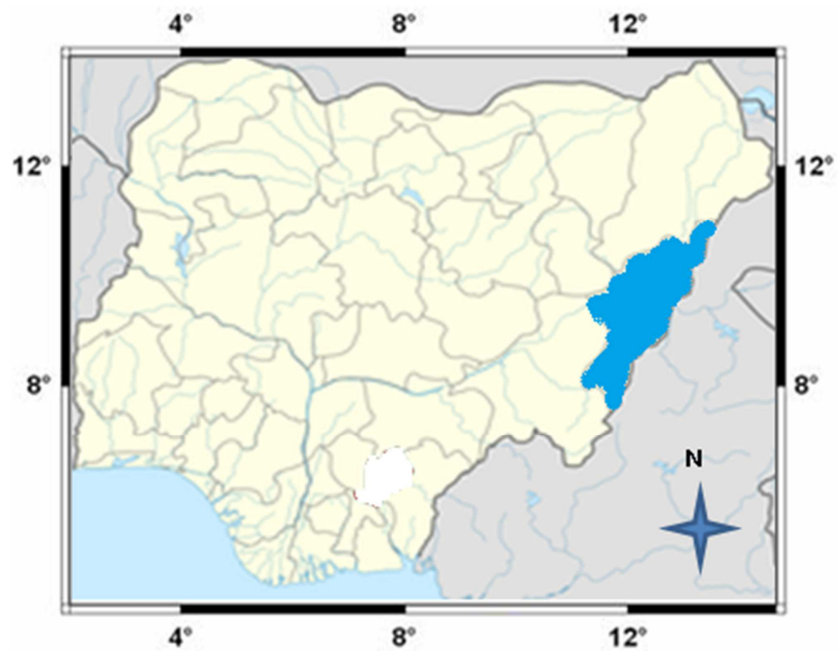

Figure 1. Map of Nigeria Showing Adamawa State, the Study Area.

According to [4], Adamawa State covers an area of land mass of about $38,741 \mathrm{~km}^{2}$. The state is divided into three Senatorial Zones (Northern, Central and Southern) as defined by [19], which are further divided into 21 Local Government Areas (LGAs) for administrative convenience, as can be seen in Figure 2.

The State has a population of $2,102,053$ persons [26]. The main ethnic groups in the state are the Kilba, Higgi, Quadoquado, Lala, Yungur, Bwatiye, Chamba, Mbula, Margi, Ga'anda, Longuda, Kanakuru, Bille, Bura, Yandang, Fali, Gude, Verre, Fulani and Libo [4, 3]. The dominant religions are Christianity and Islam, although some of its inhabitants still practice African traditional religions. The major occupation of Adamawa people is farming. The soil type is ferruginous tropical soils of Nigeria based on genetic classification of soils [17].

The state has minimum and maximum rainfalls of 750 and $1050 \mathrm{~mm}$ per annum and average minimum and maximum temperatures of $15^{\circ} \mathrm{C}$ and $32^{\circ} \mathrm{C}$, respectively. The relative humidity ranges between 20 and 30\% with four distinct seasons that include early dry season (EDS, October December); late dry season (LDS, January - March); early rainy season, (ERS, April - June) and late rainy season (LRS, July - September), according to [2, 3]. The vegetation type is 
best referred to as guinea savannah [4].

\subsection{The Study Sites}

Ten (10) Local Government Areas were used for the study which represents the three Senatorial Districts in the State, as shown in Figure 2. They include: Michika, Mubi-North, Mubi-South (Northern Senatorial District), Gombi, Girei, Jimeta, Yola-South (Central Senatorial District), Numan, Guyuk and Ganye (Southern Senatorial District).

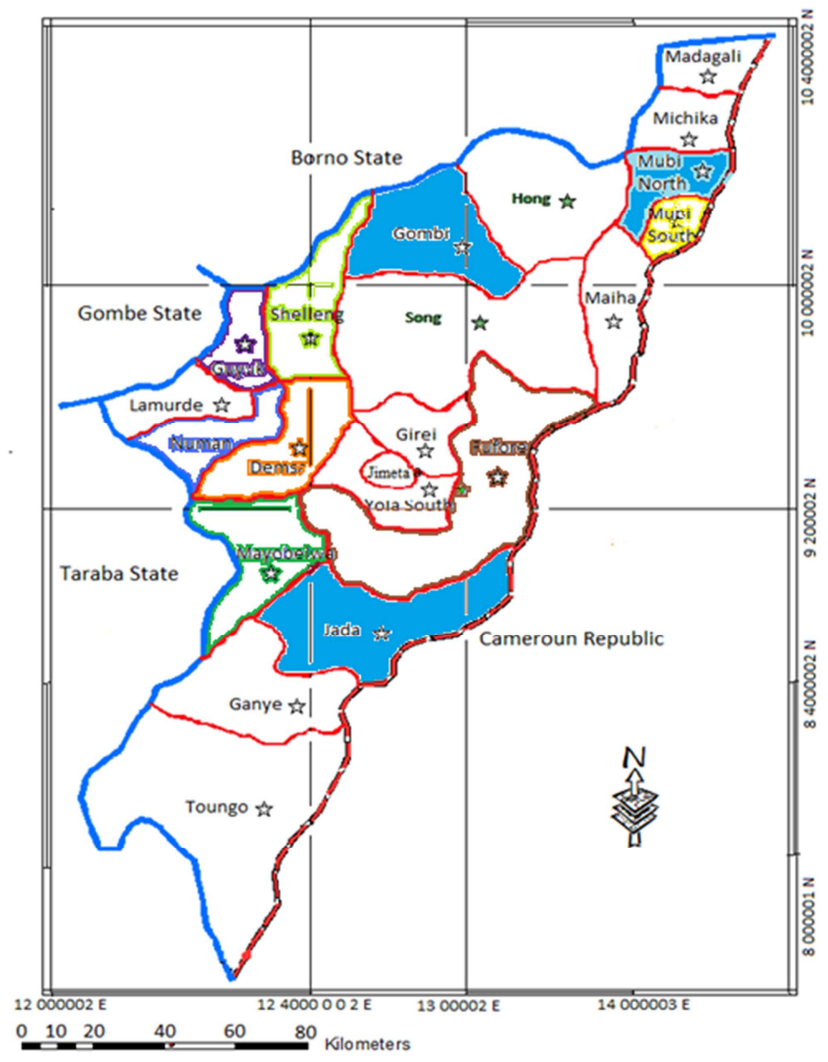

Figure 2. Map of Adamawa State Showing Study Sites.

\subsection{Selection of Respondents and Sampling Design}

The study covered a period of 3 months (January to March, 2020). During the survey, visits were paid to institutions of higher learning, health institutions, local governments' headquarters, traditional healing centres, motor parks, mechanic workshops, leisure and relaxation centres, religious centres and market places, where questionnaires were distributed randomly and respondents identified. The objectives of the study were explained to them and their permission obtained to participate in the study.

\subsection{Data Collection}

One thousand (1000) respondents, 100 from each of the ten local government areas were carefully and purposively selected for oral interviews, observations and discussions.

\subsection{Ethics Statement}

The specimens were obtained from patients without anesthesia or pain relief by certified and well-trained laboratory technologists in the hospitals following standard protocols.

\subsection{Collection of Specimens}

Urine specimens were obtained from patients via the clean-catch midstream technique, as described by [16]. Stools were collected from the rectum into the sample bottles without touching the floor. Sterilized cotton bolls were used for vaginal swabs via the vulva. Semen was collected through masturbation after three days of free sexual intercourse while prostate contents were obtained from the penile opening via prostate palpation through the rectum.

\subsection{Bacterial and Parasitological Examinations}

Out of the one thousand (1000) respondents interviewed, one hundred (100) volunteer spouses (including 50 males and 50 females) who are suffering from these problems were carefully screened and were sent to the University of Maiduguri Teaching Hospital, Federal Medical Centre Yola and the Adamawa State Specialist Hospital, Yola for culture of their urine, stool, vaginal swabs, semen and prostate contents. The specimens were also examined under the electric microscope. These were done to diagnose for urinary tract infection (UTI) that could possibly cause sexual dysfunction and infertility amongst spouses.

The procedure involved taking $0.001 \mathrm{ml}$ of urine in sterile calibrated loops, a pinch of stool, vaginal swabs, semen and prostate contents and streaked across culture plates containing solid media (blood agar and MacConkey's agar) that provide nutrients necessary for bacterial growth. Streaked plates were covered and incubated in $35^{\circ} \mathrm{C}$ incubators for a minimum of 18 hours. Plates were viewed for the presence and number of bacterial colonies [10, 14]. For parasitological examination, samples were subjected to simple floatation technique to detect oocysts and Schistosome eggs [36].

\subsection{Ultrasound Scanning}

Ultrasound scanning is a non-invasive diagnostic exam performed to assess the condition of the urinary bladders, prostate glands, kidneys and ovaries or fallopian tubes of the respondents. It is done to check for abnormalities of the size, shape and location of the organ and also detect cysts, fibroids, tumors, abscesses, obstructions, inflammations, fluid collections and infections within or around the organs. It is a fast and easy examination that takes less than an hour to complete as described by [18, $28]$.

The procedure involved spouses taking lots of fluid (1liter of water) at least an hour or two before the 
examination. The water helped to make the organs appear clearer on the ultrasound. They were asked to remove clothing, jewelry, or other objects that may interfere with the scanning processes and were given gowns to wear. They were asked to lie on an examination beds on their backs and /or stomach, depending on the organ to be examined. Ultrasound gel was applied on their abdominal areas and the devices called the ultrasound machines or transducers moved around the abdominal areas and the examination carried out.

The ultrasound machines set off high-frequency sound waves into the skins. In turn, the different organs and tissues of the body bounced or reflected off the sound waves, creating an echo in the form of images. The ultrasound machines analyzed the information from the sound waves displayed on the computer screens or monitors. These images were then stored digitally and interpreted for necessary action.

\subsection{Data Analysis}

Data generated from the survey were subjected to descriptive statistics such as frequency distribution, percentages in table format to explain the causes, signs and symptoms of sexual dysfunction and infertility amongst the spouses in the study area.

\section{Results and Discussion}

\subsection{Sexual Dysfunction and Infertility amongst Spouses in Adamawa State}

The cases of sexual dysfunction and infertility amongst spouses in the study area are showed in Table 1 . The results showed that, $88 \%$ of the spouses suffering from the conditions are youths between the ages of 20 to 40years. The conditions may not be related or attributed to old age since majority of them are still young and in their active sexual lives. The impact of these conditions on African countries and Nigeria in particular agreed with [35] that, is no longer a crisis only for the healthcare sector, but presents a challenge to all sectors of the economy. When a greater part of the nation's pool of manpower is sick, there would be short fall in major derivers of the economy like agriculture, health, education and manufacturing sectors.

It has the potential to reverse those gains made in human development in the past. The findings indicated that, only $12 \%$ are in the age bracket of 50 to 70 years. This may probably be associated with old age in addition to the infection of abdominal cavity by Schistosome species (bilharziasis). Beyond health issues, these conditions should and must globally be seen as a development concern, affecting income, social status and other direct and indirect components of human development.

Table 1. Cases of Sexual Dysfunction and Infertility amongst Spouses in Adamawa State.

\begin{tabular}{|c|c|c|c|c|c|}
\hline Senatorial District $N=100$ & Northern Adamawa & Central Adamawa & Southern Adamawa & Frequency & Percent (\%) \\
\hline \multicolumn{6}{|l|}{ Sex } \\
\hline Male & 15 & 20 & 15 & 50 & 50 \\
\hline Female & 15 & 20 & 15 & 50 & 50 \\
\hline \multicolumn{6}{|l|}{ Age } \\
\hline $20-40$ & 26 & 38 & 24 & 88 & 88 \\
\hline $50-70$ & 4 & 2 & 6 & 12 & 12 \\
\hline \multicolumn{6}{|l|}{ Marital Status } \\
\hline Single & 6 & 4 & 0 & 10 & 10 \\
\hline \multicolumn{6}{|l|}{ Years of Infection } \\
\hline $1-10$ & 20 & 32 & 26 & 78 & 78 \\
\hline 11 and Above & 10 & 8 & 4 & 22 & 22 \\
\hline \multicolumn{6}{|l|}{ Etiology/Transmission } \\
\hline Sexual Intercourse & 20 & 35 & 25 & 80 & 80 \\
\hline Others & 10 & 5 & 5 & 20 & 20 \\
\hline
\end{tabular}

The findings showed that, $90 \%$ of the spouses are married and majority of them have suffered delay in conception. After the conception, most of the pregnancies were lost due to miscarriages at the first trimester (3months old). It was gathered that, few of the married spouses suffered total lack of conception after many years of marriage, as can be seen in Table 1. This situation, according the respondents, causes serious confusion, economic lost, depression and frustration in their families. The problem is quite worrisome and could lead to conflicts and breaking of homes. The findings corroborated that of $[27,11]$, who reported a global increase in male and female sexual dysfunction, respectively. Similarly, [7, 13] again reported that, three out of every 10 Nigerian men have erectile dysfunction or other sexual problems and there is also sexual dysfunction among female patients of reproductive age in a hospital setting in Nigeria. These results again agreed with [6] who reported similar findings in their study of male reproductive health challenges: appraisal of wives coping strategies in Nigeria.

The findings showed that, only $10 \%$ of spouses are still single, though they have proposed to their fiancés and fiancées and are planning to settle down together. But for these conditions, they had a second thought and are afraid to venture into the marriage institution. According to the respondents, it is no longer important and necessary to get married since the urge, drive and confidence are not there. The results also supported [20], who reported similar findings on Schistosomiasis (bilharziasis) of the abdominal 
cavity as a serious cause of sexual dysfunction and infertility amongst couples.

The results indicated that, $78 \%$ of the spouses had the infection for 1 to 10 years while $22 \%$ had it for more than 11years, as shown in Table 1. The interviews showed that, spouses remain with the infections for longer period of time because symptoms usually appear mild from the early stage and many clinical health-care professionals are unaware of the manifestations of genital or abdominal Schistosomiasis, it is often ignored or underestimated. But symptoms gradually progress to become complicated and life threatening. The situation becomes like a monster consuming most part of the family earnings, thereby reducing family food production and economic growth. The investigations show that, damage caused by these parasites in the study area is severe. It was also gathered that, the chronic nature and complexity of the disease presents challenges to its diagnoses, control and elimination in resource-poor society like the study area.

The results of the interviews showed that, $80 \%$ of the spouses contracted the parasite through sexual intercourse, while $20 \%$ of them don't know how and where they got infected with the parasite (Table 1). According to [20], infections by Schistosome species are usually acquired by contact with still or slowly flowing water contaminated by infected urine or faeces. But the adults Schistosome species are widely distributed throughout the pelvic and mesenteric venous plexuses and oviposition usually occurs in the pelvic organs, especially in the urinary bladder, ureters, urethra, prostate and lower gastrointestinal tract. Female genital organs, ovaries, fallopian tubes and vagina have high egg burdens [20]. Therefore, transmission through sexual intercourse could be possible.

\subsection{Causes of Sexual Dysfunction and Infertility Amongst Spouses in the Study Area}

Table 2. Diagnosis of Spouses for Causes of Sexual Dysfunction and Infertility.

\begin{tabular}{|c|c|c|c|c|c|c|c|}
\hline Specimens / Diagnosis & Urine/Stool & $\begin{array}{l}\text { Vaginal } \\
\text { Swabs }\end{array}$ & Semen & $\begin{array}{l}\text { Prostate } \\
\text { Content }\end{array}$ & $\begin{array}{l}\text { Prostate } \\
\text { Glands }\end{array}$ & Bladders/Kidneys & $\begin{array}{l}\text { Ovaries/Fallopian } \\
\text { Tubes }\end{array}$ \\
\hline $\begin{array}{l}\text { Bacterial Culture } \\
\text { Gonorrhea/ Staphylococcus } \\
\text { Parasitic Microscopic Examination } \\
\text { Schistosomiasis } \\
\text { Ultrasound Scanning } \\
\text { Abnormality }\end{array}$ & $\begin{array}{l}- \\
+\end{array}$ & $\begin{array}{l}- \\
+\end{array}$ & $\begin{array}{l}- \\
+\end{array}$ & $\begin{array}{l}- \\
+\end{array}$ & . & + & 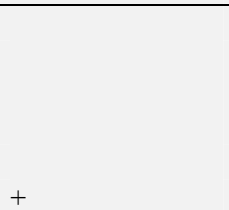 \\
\hline
\end{tabular}

Table 2 shows the results of the culture of urine, stool, vaginal swabs, semen and prostate content of all the spouses. There were no bacterial growths found and no organism isolated from the test carried out. However, the microscopic examinations revealed the presence of Schistosome species which causes Schistosomiasis (bilharziasis), as can be seen in Table 2. The results agreed with [20], who reported similar findings on Schistosomiasis (bilharziasis) of the abdominal cavity as a cause of sexual dysfunction and infertility amongst couples.

Table 3. Ultrasound scanning of the Prostate Glands, Bladders, Kidneys and Ovaries/Fallopian tubes.

\begin{tabular}{|c|c|c|c|c|c|}
\hline Parameters $N=100$ & Prostate Glands & Bladders/Kidneys & Ovaries fallopian & Frequency & Percent (\%) \\
\hline \multicolumn{6}{|l|}{ Sex } \\
\hline \multirow[t]{2}{*}{ Male } & $+(30)$ & $+(30)$ & & 30 & 60 \\
\hline & $-(20)$ & $-(20)$ & & 20 & 40 \\
\hline \multirow[t]{2}{*}{ Female } & & $+(10)$ & $+(10)$ & 10 & 20 \\
\hline & & $-(40)$ & $-(40)$ & 40 & 80 \\
\hline
\end{tabular}

Table 3 shows the ultrasound scanning of the prostate glands, bladders, kidneys and ovaries or fallopian tubes of the male and female spouses, respectively. The results revealed that, $60 \%$ of the male spouses between the ages of 20 to 40years with infection for more than 11years had prostate inflammation or enlargement, distended kidneys with blackish patches and tumult indicating signs of infections by the parasite. Fourty percent of the male spouses with infection for a period of 1 to 10years manifest mild signs and symptoms without complication arising from prostate and kidney abnormalities.

Similarly, twenty percent of the female spouses with infection for more than 11years had abnormalities of the kidneys, ovaries and fallopian tubes with cases of ovarian cysts and fibroid (Table 2). This may also be attributed or linked to Schistosomiasis (bilharziasis) of the abdominal cavity in addition to complications arising from other reproductive diseases of female spouses. Furthermore, eighty percent of the female spouses with infection for 1 to 10 years manifested mild symptoms without serious signs of abnormalities of the kidneys, ovaries and fallopian tubes (Table 5)

\subsection{Clinical Signs and Symptoms Shown by the Male Spouses}

Table 4 shows thirty (30) different clinical signs and symptoms manifested by male spouses. The results of the interviews showed that, three days after infection, the first 
symptom manifested by the male spouses were sharp biting pain from the penis and drops of blood at the end of urination (haematuria). This may probably indicate an infection of the urinary bladder caused by genital or abdominal Schistosome species (bilhazziasis). As the condition persists, the symptoms increased to burning sensation and difficulty when urinating (dysuria). This could also be linked to an infection of the urinary tract (urethra) which caused serious pains and discomfort to males.

Table 4. Clinical Signs and Symptoms Shown by the Male Patients in the Study Area.

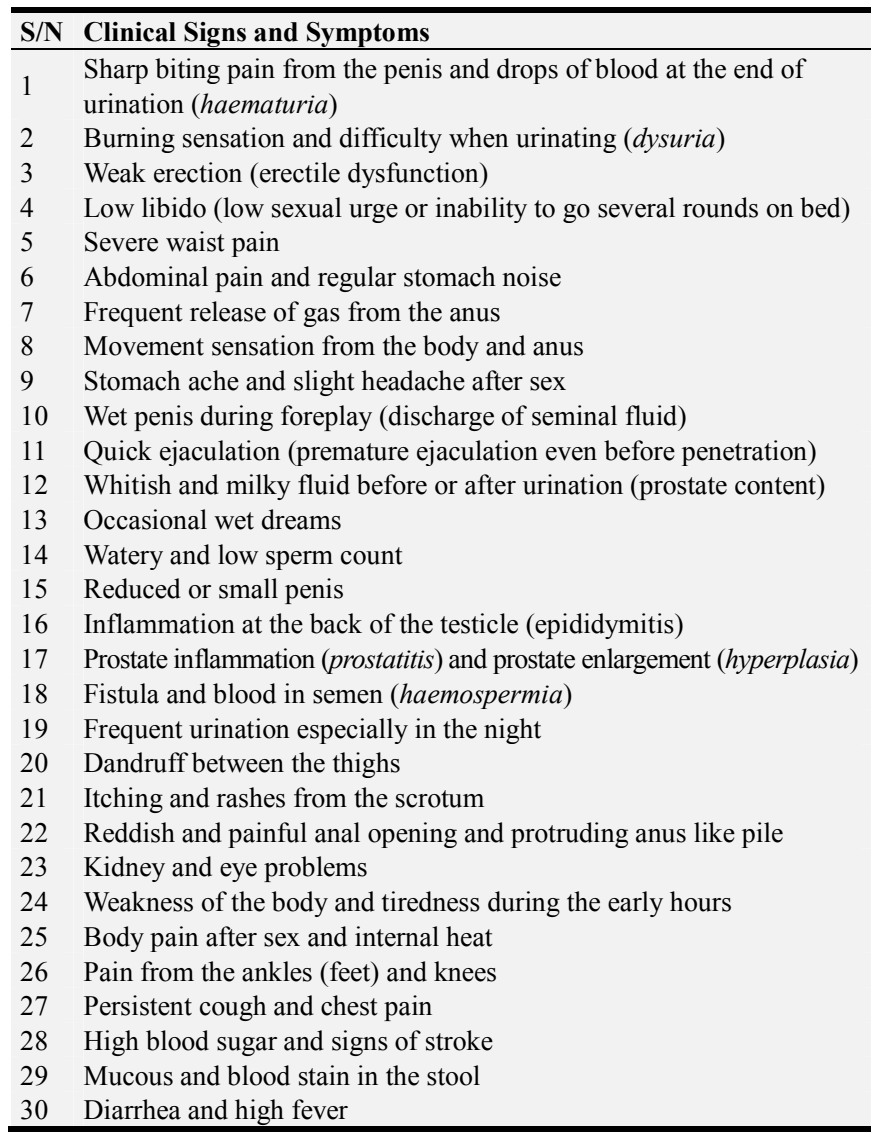

The parasite multiplies very fast and spreads to other parts of the body like the prostate causing inflammation at the back of the testicle (epididymitis) which simulates possible fistulization, prostate inflammation (prostatitis), prostate enlargement (prostate hyperplasia) and blood in semen (haemospermia). The combination of the above is most likely the cause of the severe waist pain suffered by the male spouses. This lowers the reproductive and economic performance of the affected parties. Waist pain may not allow male spouses to put more man-hours in farming and other businesses to earn enough for their families and contribute to the national economic growth or GDP. The complications might have been responsible for hormonal imbalances which again results to weak erection (erectile dysfunction), low libido (low sexual urge or inability to go several rounds on bed), wet penis during foreplay (discharge of seminal fluid), quick ejaculation (premature ejaculation even before penetration), whitish and milky fluid before or after urination (prostate content), occasional wet dreams, watery semen, low sperm count (impotence), frequent urination especially in the night and reduced or small penis.

In the advanced stage of the infection, the male spouses also experienced itching and rashes from the scrotum, dandruff between the thighs, abdominal pain, regular stomach noise, stomach ache after sex, slight headache, movement sensation from the body and anus, reddish and painful anal opening, protruding anus like pile and frequent release of gas from the anus.

Table 5. Clinical Signs and Symptoms Shown by the Female Patients in the Study Area.

\begin{tabular}{ll}
\hline S/N & Clinical Signs and Symptoms \\
\hline 1 & Virginal discharge (Leucorrhoea) \\
2 & Itching and burning sensation from the vulva \\
3 & Abdominal and pelvic cavity pain \\
4 & Painful coitus (dyspareunia) \\
5 & Stomach noise and ache after sex \\
6 & Frequent release of gas from the anus \\
7 & Excessive pain during menstruation (Dysmenorrhea) \\
8 & Slight headache \\
9 & Post-coital bleeding or simple contact bleeding \\
10 & Reddish, painful anal opening and protruding anus like pile \\
11 & Movement sensation from the body and anus \\
12 & Dandruff between the thighs \\
13 & Low libido (loss of interest or desire for sex) \\
14 & Lack of arousal and orgasm \\
15 & Irregular and black menstruation (menstrual disorders) \\
16 & Delay in conception \\
17 & Inflammation of the cervix (cervicitis) \\
18 & Inflammation of the endometrium layer (endometritis) and/or \\
19 & fallopian tubes (Salpingitis) \\
20 & Regular miscarriages \\
21 & Widney problems \\
22 & Internal heat \\
23 & Body pain after sex \\
24 & Eye problems \\
25 & Pain from the ankles (feet) and knees \\
26 & Persistent cough and chest pain \\
28 & High blood sugar \\
30 & Signs of stroke \\
\hline
\end{tabular}

The parasite also migrates to infect the kidneys resulting to some blackish patches from the interior part of the organ. When the kidneys are impaired or compromised, a lot of complications set in leading to weakness of the body and tiredness (lack of stamina and difficulty in coming out of bed during the early hours), body pain after sex, eye problems, internal heat, pain from the ankles (feet), pain from the knees, persistent cough, chest pain, high blood sugar, sign of stroke, mucous and blood stain in the stool, diarrhea and high fever. These conditions again caused food insecurity, economic meltdown, sexual dysfunction and infertility in male spouses in the study area. Beyond mortality rate, the burden of the diseases compound socio-economic costs in terms of productivity losses, care and treatment, hospitalization and handicap in the society [23]. 


\subsection{Clinical Signs and Symptoms Shown by the Female Spouses}

Table 5 shows thirty (30) signs and symptoms manifested by female spouses. The results of the interviews showed that, female spouses do not usually detect symptoms of reproductive infections on time unlike the case of males. This may be due to the nature of their physiological and gynecological set-up. It could also be that, female folks are always full of activities and are not careful to observe changes in their body systems on time. It may also be that, they don't open up or are shy to discuss such problems. The infection takes time before they disclose the symptoms.

Mild infections manifest symptoms such as virginal discharge (leucorrhoea), itching and burning sensation from the vulva, abdominal and pelvic cavity. They also experience painful coitus (dyspareunia), stomach noise and ache after sex, frequent release of gas, excessive pain during menstruation (dysmenorrhea), slight headache, post-coital bleeding or simple contact bleeding, reddish and painful anal opening and protruding anus like pile, movement sensation from the body and anus, dandruff between the thighs, low libido (loss of interest or desire for sex), disorder in arousal and orgasm.

In severe and critical cases, they manifest symptoms like irregular and black menstruation (menstrual disorders), delay in conception, inflammation of the cervix (cervicitis), inflammation of the endometrium layer (endometritis) and fallopian tubes (salpingitis) and regular miscarriages.

Infection of the kidney also showed some blackish patches from the interior part of the organ. This may be reasons for the weakness of the body and tiredness (lack of stamina and difficulty in coming out of bed during the early hours), internal heat, body pain after sex, eye problems, pain from the ankles (feet), pain from the knees, persistent cough, chest pain, high blood sugar, signs of stroke, mucous and blood stain in the stool, diarrhea and high fever.

These gynecological ailments affected negatively the sexual activities and fertility rate of female spouses in the study area. These not only carry huge risks to females but their impact on mental health and social status cannot be underestimated. Infertility can be a taboo in many cultures and can lead to a broader range of issues such as stigma, economic difficulties, social exclusion and isolation in the society.

The findings corroborated that of [20] who reported that, pathology of genital or abdominal Schistosomiasis (bilharziasis) is like other sexually transmitted diseases and when spouses present themselves to a local health care facility with these symptoms, they are often misdiagnosed due to lack of awareness and clear diagnostics procedures. Thus, spouses often receive wrong treatments and are said to be non-responsive to treatment.

\section{Conclusion}

It was concluded that, sexual dysfunction and infertility are more prevalent amongst young spouses aged between 20 to 40 years in Adamawa State. The conditions are majorly caused by parasites called abdominal Schistosome species contracted through sexual intercourse.

The parasite after infecting its victim, dwells in the blood system, multiplies very fast and spreads to abdominal cavity, urinary bladders, ureters, urethra, prostates, kidneys and the lower gastrointestinal tracts to cause genital Schistosomiasis (bilharziasis). Female genital organs, ovaries and fallopian tubes harbour high egg burdens. These conditions result to sexual dysfunction and infertility amongst spouses, provoke other ailments such as stomachache, body pain, waist pain, headache, eye problem, high blood sugar, diarrhea and even death, if not treated on time.

It was gathered that, the parasite completely defied most medical solutions as it is very resistant to most conventional de-wormers and antibiotics. This could probably be that, the right drug is not administered since it is one of the most neglected diseases of tropical Africa. Men with these conditions are not able to satisfy their spouses on bed and similarly, women with these cases don't have feelings and hate sex.

These conditions are the true reflection of what is obtainable in North-Eastern Nigeria and other parts of the country. Investigations showed that, the men and women suffering from these conditions are traumatic, psychologically frustrated, physically weak and emotionally imbalanced. These problems are probably the cause of decreasing reproductive health, food in-sufficiency and economic dwindling in the region. These may also be responsible for the increase in marital conflicts, instability, disintegration and violence consequently resulting to separation or divorce in the study area.

\section{Recommendations}

Health is wealth; therefore the general public is advised to seek and access good health care facilities at regular intervals to prevent sexual dysfunction and infertility which leads to low reproductive performance and economic recession, break-up of marriages and loss of lives.

This study, therefore, generated information that could be used by medical experts and the general public to optimize sexual life of spouses in the study area. It could, also, contribute to the actual decision frame-works of immediate local authorities on human reproductive health.

Future in-depth investigation of the problem should be carried out to define genital Schistosomiasis (bilharziasis) in spouses to develop practical diagnostic tests and to improve treatment platforms and outcomes. There should be proper sensitivity for the diagnosis of mild infections caused by this parasite and monitor the efficacy of any chemotherapy.

Finally, the research team has discovered a local therapy that could be used for the cure of genital Schistosomiasis (bilharziasis) in Adamawa State. Government should therefore support the development of this local drug to serve as an intervention programme in Nigeria and elsewhere in the world. 


\section{References}

[1] AAFP/AFP (2015). American Academy of Family Physicians/American Family Physician - Female Sexual Dysfunction: Evaluation and Treatment.

[2] ADADP. (1986). Adamawa Agricultural Development Programme. Methods of Vegetable Gardening, pp. 3-4.

[3] Adebayo, A. A. (1999). Climate, Sunshine, Temperature, Relative Humidity and Rainfall. Journal of Applied Sciences and Management, 1, 69-72.

[4] Adebayo, A. A., \& Tukur, A. L. (1997). Adamawa State in Maps. Paraclete Publishing Company Yola, Adamawa State, Nigeria, pp. 8-45.

[5] Afsaneh, B., Zahra, B., \& Fatemeh, N. (2016). Sexual Dysfunction in Women Undergoing Fertility Treatment in Iran Prevalence and Associated Risk Factors. Journal of Reprod. Infertil., 17 (1), 26-33.

[6] Amoo, O. E., Omideyi, K. A., Fadayomi, O. T., Ajayi, P. M., Oni, A. G., \& Idowu, E. A. (2017). Male reproductive health challenges: appraisal of wives coping strategies. Reproductive Health, 14, 90.

[7] Amoo, E. O., Oni, G. A., Ajayi, M. P., Idowu, A. E., Fadayomi, T. O., \& Omideyi, A. K. (2015). Are men's reproductive health problems and sexual behavior predictors of welfare? Am. Journal of Mens Health.

[8] ARHP (2015). Association of Reproductive Health Professionals: Size Up Your Sex Life.

[9] ASMLS (2010). Map of Nigeria Showing all States. Adamawa State Ministry of Land and Survey, Yola, Nigeria.

[10] Bale, M. J., \& Matsen, J. M. (1981). Evidence against the practicality and cost-effectiveness of a gram-positive coccal selective plate for routine urine cultures. Journal of Clinical Microbiology, 14, 617-9.

[11] Basson, R., Berman, J., Burnett, A., Derogatis, L., Ferguson, D., \& Fourcroy, J. (2000). Report on the international consensus development conference on female sexual dysfunction: definition and classification. Jurnal of Urol, 163, 688-893.

[12] Benagiano, G., Carrara, S., \& Filippi, V. (2010). Sex and reproduction: an evolving relationship. Hum Reprod Update, $16(1), 96-107$.

[13] Benjamin, A. F., Ernest, O. O., \& Adenike, O. A. (2007). Sexual Dysfunction among Female Patients of Reproductive Age in a Hospital Setting in Nigeria. Journal of Health Popul Nutr., 25 (1), 101-106.

[14] Carroll, K. C., Hale, D. C., Von Boerum, D. H., Reich, G. C., Hamilton, L. T., \& Matsen, J. M. (1994). Laboratory evaluation of urinary tract infections in an ambulatory clinic. American Journal of Clinical Pathology, 101, 100-3.

[15] Clark, S., \& Brauner-Otto, S. (2015). Divorce in sub-Saharan Africa: are unions becoming less stable? Popul Dev Rev., 41 (4), 583-605.

[16] Clarridge, J. E., Johnson, J. R., \& Pezzlo, M. T. (1998). Cumitech 2B: laboratory diagnosis of urinary tract infections. Washington, DC: American Society for Microbiology.
[17] FAO (1996). Trypanotolerant Cattle and Livestock Development in West and Central Africa. Animal Production Health Paper, 2, 213-230.

[18] Fischbach, F. T., \& Dunning, M. B. (2009). Manual of Laboratory and Diagnostic Tests, 8th ed. Philadelphia: Lippincott Williams and Wilkins.

[19] INEC (1996). Independent National Electoral Commission. Nigerian Electoral Body Responsible for Organization and Conducting General Elections.

[20] Katsetos, C., Kontoyannis, M., Koumousidis, A., Petroyannis, N., \& Davies, A. (2013). Schistosomiasis of the abdominal cavity and infertility: a case report. OA Case Reports, 2 (6), 57.

[21] Keye, W. R. Jr. (1984). Psychosexual responses to infertility. Clin Obstet Gynecol., 27 (3), 760-6.

[22] Laumann, E. O., Palk, A., \& Rosen, R. C. (1999). Sexual dysfunction in the United States: Prevalence and predictors FREE. Journal of the American Medical Association, 281 (6), 537-544.

[23] Mathers, C. D., Ezzati, M., \& Lopez, A. D. (2007). Measuring the burden of neglected tropical diseases: the global burden of disease framework. PLOS Negl Trop Dis. Journal.

[24] Masters, W. H., \& Johnson, V. E. (1996). Human sexual response. Boston: Little, Brown.

[25] Mohammed, K. (1999). Historical background. In A. A. Adebayo and A. L. Tukur (Ed) Adamawa State in Maps. Paraclete Publishers, Yola.

[26] NPC (1991). National Population Commission. Nigerian Agency Responsible for Conducting Census.

[27] Omisanjo, O., Fabola, O., Aleetan, O., Babatunde, A., Taiwo, A., \& Ikuerowo, S. (2014). Prevalence and treatment pattern of erectile dysfunction amongst men in southwestern Nigeria. Internet Journal of Sex Med., 3 (1), 1-4.

[28] Pagana, K. D., \& Pagana, T. J. (2010). Mosby's Manual of Diagnostic and Laboratory Tests, 4th ed. St. Louis: Mosby Elsevier.

[29] Phillips, N. A. (2000). Female sexual dysfunctions, evaluation, and treatment. Am Fam Physician, 62, 127-36.

[30] PP (2015. Planned Parenthood: Sex and Sexuality.

[31] Ryan, K. J., \& George, R. C. (2003). Sherris Medical Microbiology: An Introduction to Infectious Disease. New York: McGraw-Hill Medical.

[32] Sigg, C. (1994). Sexuality and sterility. Ther Umsch., 51 (2), $115-9$.

[33] WebMD (2018). Health Solutions. WebMD Newsletters.

[34] WHO (2019). World Health Organization Newsletters.

[35] WHO (2003). Global defense against the infectious diseases threat. Geneva: World Health Organization.

[36] Zajac, A. M., \& Conboy, G. A. (2012). Veterinary Clinical Parasitology. 8th ed. UK. Willy Blackwell press. 